\title{
Clave y cónclave. La codificación ética del desempeño antropológico
}

\author{
José Sánchez Jiménez
}

Después de analizar la estructura normativa de algunos códigos de ética para la antropología, se propone una forma de codificación que incorpore la relación entre axiología, dimensiones de responsabilidad en el obrar antropológico y lo que aquí se denomina como "continuum antropológico".

PALABRAS CLAVE: codificación, operadores normativos, axiología, responsabilidad, continuum antropológico

\section{Code and Conclave: The Ethical Codification of Anthropological Work}

After analyzing the normative structure of some ethical anthropological codes, this article proposes a way of codification that includes relationships into axiology, dimensions of responsibilities in the anthropological deeds and what is called here anthropological continuum.

KEYWORDS: codification, normative operators, axiology, responsibility, anthropological continuum 


\section{INTRODUCCIÓN}

$\mathrm{L}$ a elaboración de códigos de ética profesional surge de la relación intrínseca entre realizar un buen trabajo y el desempeño ético (Gardner, Csíkszentmihályi y Damon, 2002).Defenderé la tesis de que sin escalas o jerarquías de valores no es posible evaluar normativamente el desempeño de una profesión. Argumentaré a favor de un modelo normativo que nos permita evaluar, mediante operadores deónticos, el desempeño ético del antropólogo. Veremos que el tema del obrar responsable otorga una dimensión axiológica a los fenómenos morales emergentes en el desempeño del antropólogo. Comenzaré con el análisis de la estructura conceptual y normativa de los códigos éticos, tomaré como ejemplos los elaborados por la American Anthropologist Association (AAA) de Estados Unidos y el Colegio de Antropólogos de Chile (CAch). Ambos países, Estados Unidos y Chile, comparten ideales sobre la libertad para investigar, el derecho informantes. Después desarrollaré la discusión en torno a un modelo evaluativo de carácter deóntico para el desempeño de la profesión antropológica, y finalmente propondré una codificación que permita situar la ética antropológica entre la axiología y las dimensiones de responsabilidad en el continuum antropológico.

\section{DIÁLOGO ENTRE CÓDIGOS}

Los códigos de ética profesionales establecen límites a lo que un profesionista puede y debe hacer dentro del marco de su disciplina. El ejercicio de una profesión demanda del profesante tres niveles de compromiso (Cortina, 2000: 14-15): a) quien ingresa a una profesión intenta alcanzar la meta que le otorga sentido; b) la profesión no es una actividad individual sino compartida, pues quienes ejercen una profesión comparten sus métodos y el ethos que la

caracterizan, y c) al ingresar en una comunidad profesional, el profesionista adquiere una identidad y un sentido de pertenencia. En síntesis, toda actividad profesional implica para el profesionista el sentido de una doble relación, estructural-estructurante, que lo sitúa como personae, es decir, como una persona pública cuyas actividades tienen lugar en el espacio de visibilidad pública. Las acciones de los antropólogos han sido recientemente cuestionadas en este espacio, tanto por los partícipes de la antropología como por la sociedad. Para enfrentar los cuestionamientos se han formado comités de ética que parten de criterios de observancia de los niveles de compromiso del antropólogo con la ética de la responsabilidad. Aquí es donde encontramos las primeras dificultades sobre la viabilidad de los códigos de ética para el desempeño antropológico. Antes de exponer las posiciones centrales en torno a los códigos de ética es necesario hacer valer la distinción entre ética y desempeño profesional. No se trata de lo mismo y tampoco de una relación unilateral en la que la aplicación de la primera se convierte en el baremo de la segunda. Para decirlo con Victoria Camps:

\footnotetext{
La ética no es nada más que la respuesta que pretende dar sentido, dirigir, las varias dimensiones de la existencia, o compensar las muchas insuficiencias y sinsabores que la vida trae consigo. En tanto respuesta, la ética ha de ir, pues, a la zaga de los problemas que van apareciendo e, inevitablemente, ha de contaminarse de las incertidumbres y miserias que ellos plantean (Camps, 2005: 9).
}

Esta definición habilita una tercera opción frente a las oposiciones que se establecen de manera habitual entre universalismo y particularismo. En otras palabras, entre una posición kantiana y una más bien hegeliana. La ética kantiana defiende la idea de un deber ser absoluto que se opone a la capacidad moral humana. Formalmente, se podrían establecer los principios éticos que rigen las acciones, independientemente de los cauces de acción y de las condiciones particulares de ésta. Estos códigos, cuya función sería juzgar las costumbres, colocarían en 
predicamento constante a las acciones, de manera que, como se deriva de la crítica hegeliana de la moralidad universal: "Si obrar moralmente consiste en asumir el puro deber, siempre será preciso renunciar a obrar" (Camps, 2005: 12). Hegel opone una conciencia moral concreta a la conciencia trascendental kantiana. Sólo desde la imperfección es posible juzgar las acciones: todo acto conlleva siempre el resultado efectual de su falibilidad. No se puede, por tanto, juzgar a priori las acciones sin incurrir en juicios arbitrarios. Podemos hablar entonces de contextualización y de luchas por el reconocimiento. ¿Cómo superar el subjetivismo? ¿Cómo obtener el reconocimiento? Estos dos aspectos, que destaca Camps a propósito de la posición particularista de Hegel, nos permitirán situar la discusión sobre el carácter normativo de los códigos de ética para la antropología. Se trata de la oposición entre dos tipos de ética, que Nishida (1995) a su vez enuncia como "heterónoma" versus "autónoma". Una ética heterónoma es aquella cuyos imperativos morales son impuestos culturalmente, mientras que una ética autónoma otorga libertad al individuo para elegir los cauces de acción, bajo el entendido de que su obrar comulga con un deber ser. Por su parte, Camps defiende la tesis de que, dado que la razón es impura, la ética ha de ser imaginativa. En consecuencia: "nadie tiene la seguridad total y absoluta sobre lo que se debe hacer" (Camps, 2005: 10). Esta posición aproxima la versión ética de Camps con la práctica, es decir, con "unos principios más adaptados a las circunstancias" (Camps, 2005: 10).

Camps decide asumir una perspectiva crítica desde la mediación entre los principios universales y la singularidad de los conflictos. Con ello logra mantenerse la reflexión ética más apegada a la realidad y menos divorciada de la acción. Esta posición se aproxima a Hegel. A diferencia de la ética kantiana, que sitúa la representación de la ley por la conciencia, habilitando una posición solipsista, Camps propone recuperar lo que a su juicio constituye la simiente de una ética comunicativa en Hegel y que consiste en "elevar la certeza particular a universal a través del lenguaje: expresar su convicción y hacer que el otro la reconozca y la comprenda" (Camps, 2005: 10). Por extensión, y abonando a la discusión sobre códigos de ética en antropología y el desempeño profesional, podemos afirmar que es en el plano de las acciones que devienen conflictuales, de manera emergente, donde surgen los problemas éticos en el desempeño de una profesión. Un acto que contraviene el sentido de una profesión, además de situar en predicamento al profesante de una disciplina, también contraviene los ideales de una comunidad de habla. Cuando esto sucede se apela al reconocimiento y a la comprensión para dirimir controversias éticas a través del lenguaje. Los conflictos sitúan la discusión sobre lo que es justo y bueno, es decir, se distingue entre lo público y lo privado en aras del bien común (Thiebaut, 1992: 41). Justamente, lo que vincula ética y antropología es el bien común. La antropología contribuye a la ampliación de la esfera pública y los derechos civiles hacia los derechos culturales. En la búsqueda del bien común se amplía nuestro sentido de lo que consideramos bueno, deseable y posible en cada caso.

En el dominio de la antropología social, el imperativo ético ha sido mantenerse a buen resguardo de alterar el contexto cultural de los sujetos y respetar el punto de vista nativo. Cuando los antropólogos han sorteado estos dos problemas con éxito, podría decirse que han realizado un buen trabajo. Pero en el ámbito de las relaciones sociales y sus contextos de producción, obrar responsablemente no se limita al plano de las acciones emprendidas por el individuo. Desde el momento en que el trabajo de campo implica al etnógrafo con sus colaboradores nativos, las acciones del primero están situadas y constantemente contextualizadas. De manera que un código de ética que se ciña a principios universalistas de tipo kantiano anularía la posibilidad misma del obrar antropológico en la producción de conocimiento socialmente relevante. Sin embargo, el particularismo hegeliano tampoco sería una solución a este problema, puesto que las luchas por el reconocimiento en el plano antropológico supondrían una 
cierta simetría en las relaciones sociales, y es claro que por más que el antropólogo logre la empatía con sus pares hay situaciones en las que no incurriría aun cuando simpatizara con sus colaboradores etnográficos. Lo mismo valdría para los nativos que por alguna razón deciden tener empatía con el etnógrafo. Dilemas de este tipo se han presentado en la historia de la antropología y sobre ellos se ha ejercido la crítica para la redefinición de la disciplina: crítica del colonialismo (Stocking, 1991; Asad, 1973), reconfiguración del pensamiento antropológico desde el orientalismo (Said, 2009), crítica de la razón poscolonial (Spivak, 2010: 7), inversión de las categorías insulares de la antropología por aquellas más bien contextuales e históricas (Mignolo, 1998), crítica de la hegemonía desde la subalternidad (Guha, 1988; Grupo Latinoamericano de Estudios
Sub-alternos, 1998), crítica de la escritura antropológica por incurrir en reduccionismos de género, identidad y alteridad (Clifford y Marcus, 1991; Marcus y Fischer, 1986), entre otros. El análisis ético de estos hitos en la historia de la antropología desborda con mucho la intención del presente texto. En cambio, analizaré la estructura de dos códigos de ética en antropología, donde se traducen diversos imperativos de carácter normativo con la finalidad de allanar el camino que nos permitirá asumir una posición intermedia para una codificación ética del desempeño antropológico. Comenzaremos por el análisis de las concreciones. Tomaremos como punto de partida los códigos de ética de la AAA y del cAch, y luego continuaremos con nuestra propuesta de codificación ética del desempeño antropológico.

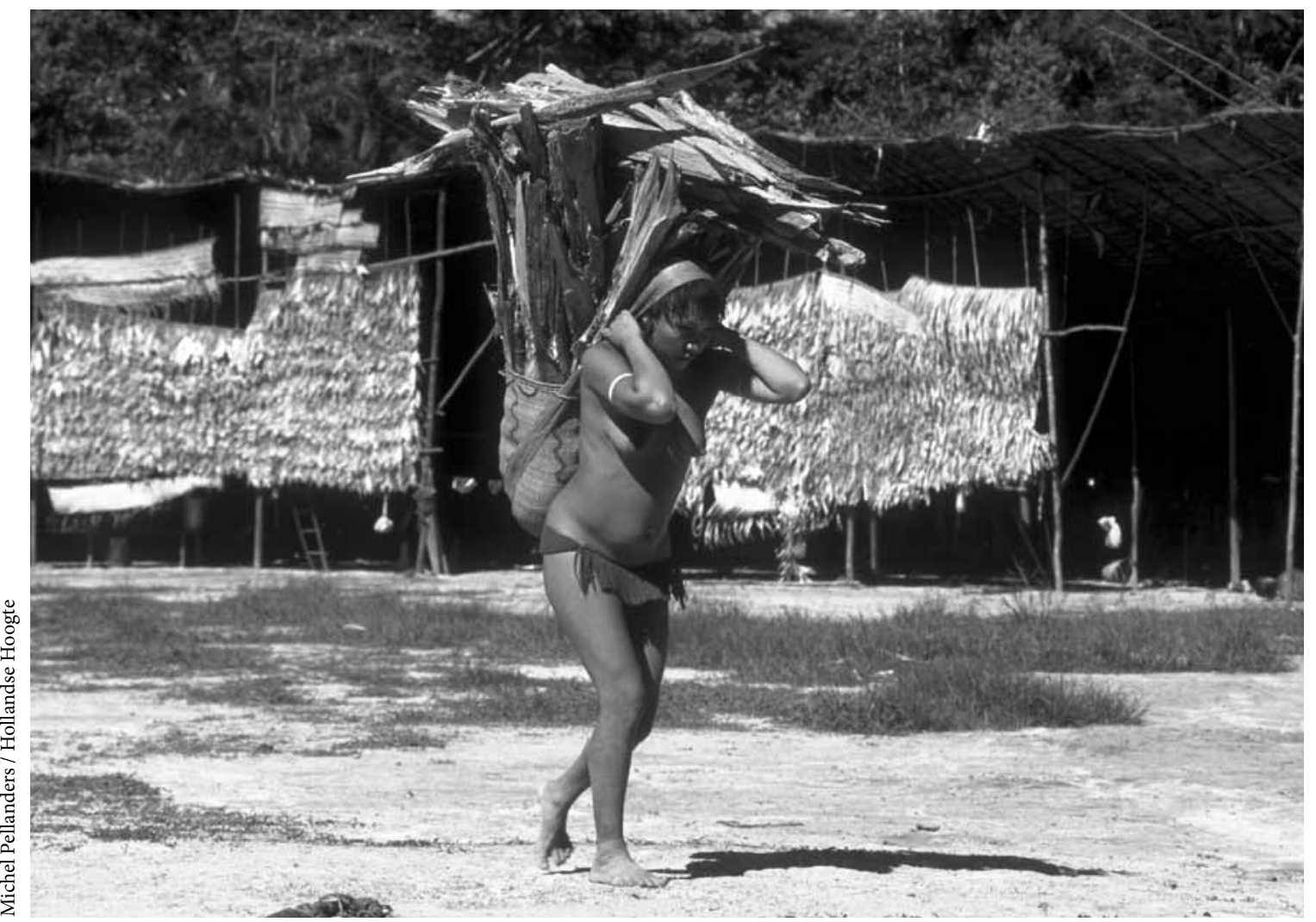

Mujer yanomami lleva pesada carga de leña. Tootobi, Roraima, Brasil, 1996. 
El código de ética de la AAA, aprobado en 1998, está estructurado en ocho partes. En el preámbulo se define el ámbito de aplicación del código y se afirma el particularismo de las reglas morales y el conflicto de los puntos de vista. El segundo apartado introduce la antropología como un campo multidisciplinario e iguala razones prácticas con razones morales. En el tercer momento se alude a la investigación y el grado de compromiso que el antropólogo establece con aquellos que financian los proyectos y la responsabilidad en la producción, el manejo y el uso de la información. En esta dirección se enlistan y se distinguen tres niveles de responsabilidad del antropólogo: 1) con los seres vivos y la ecología; 2) con los pares académicos y estudiantes, y 3) con lo público. El cuarto apartado se dedica al ámbito de la enseñanza. Enseguida se destinan algunos párrafos a valorar la ética en el plano de la antropología aplicada. Después vienen los agradecimientos a colaboradores y se alude al proceso que llevó a los comités que elaboraron el código de ética de la AAA a terminarlo en un lapso que va de 1995 a 1997. Por último, se hace referencia a otros códigos de ética que complementan el interés del lector.

Por su parte, el código de ética del cach, aprobado en 2007, consta de una sección de antecedentes, los cuales definen el carácter relacional del vínculo entre antropólogos y personas, y establecen los límites que debe respetar "todo acto profesional" a favor de los valores universales consignados en la Declaración de los derechos humanos. Posteriormente se enlistan los objetivos específicos del código con un claro énfasis en el papel que juegan los evaluadores para valorar los conflictos éticos. Se distinguen tres niveles normativos en el uso de los operadores "éticos": "respeto hacia", "derechos a" y "deberes hacia”. En la parte final se describe el procedimiento que hace valer el código de ética y el papel de los evaluadores para resolver las controversias que afectan la reputación del antropólogo. El análisis cualitativo de los códigos, con el software NVivo 8, nos permitió realizar las siguientes operaciones analíticas sobre el universo semántico de los códigos de ética de ambos países. En primer lugar se buscó la frecuencia textual de las primeras 1000 palabras con una extensión mínima de cinco caracteres. Enseguida se seleccionaron las palabras con mayor frecuencia de uso con el objetivo de localizar el plexo de sentido de los códigos. Lo que encontramos es el uso de operadores normativos y un uso recurrente de frases con carácter regulatorio de actividades y de agentes. La estructura formal de los códigos puede sintetizarse así: 1) definiciones de código; 2) uso de operadores normativos; 3 ) derechos y obligaciones, y 4) responsabilidades. A continuación se elici$\tan$ los hallazgos.

\section{DEFINICIONES DE CÓDIGO}

En cinco párrafos de texto del código de ética de la AAA localizamos el sentido de uso de la palabra "código": es un conjunto de principios y lineamientos, un marco de trabajo y una guía que tienen como objetivo proporcionar herramientas al antropólogo para tomar decisiones éticas o fundar sus juicios y elecciones con base en él. El código tiene como propósito alentar la discusión, la educación y el entrenamiento. El antropólogo, docente o investigador, debe enseñar a tomar decisiones éticas mediante ejemplos y casos de estudio, aludiendo a lo que idealmente sería "la manera apropiada" para decidir éticamente. Además, el código no puede anticiparse a las circunstancias o situaciones específicas o a las acciones derivadas de éstas. El antropólogo en su función de actor racional debe ser cuidadoso en la elección ética de los cauces de acción, y en su carácter electivo y accionalista puede fundar sus elecciones en presupuestos, hechos y temas sobre los cuales ejerce la elección. Ésta supone que el hombre es libre de elegir. El acto antropológico es concebido como intencional o teleológico. Si las elecciones del antropólogo se basan en el código de ética, entonces actúa conforme a prescripciones. Pero si la justificación es posterior a los actos, entonces no siempre es posible anticiparse al sentido de éstos, y 
por consecuencia lo experimental flota en el contexto de los impactos.

El antropólogo debe informarse acerca de los códigos éticos, entrenarse en la resolución de controversias y promover el consentimiento informado de los códigos, leyes y regulaciones que afectan a sus proyectos de investigación. Como mecanismo de control para garantizar la racionalidad del obrar antropológico se encuentran los pares, colegas, académicos, la docencia y el entrenamiento ético en trabajo de campo o en el aula. El énfasis educativo y electivo del código se traduce en una ética de consumo que ha sido conceptuada como reaganethics, cuyo correlato social en la década de 1980 se puede observar en la necesidad social de educarse en el control de la alteridad y el diálogo mediante el manejo empresarial de la imagen del self (Tseëlon, 1992).

El cach define el código como un instrumento para facilitar el cumplimiento de los Estatutos del Colegio y concibe la ética como un valor de la profesión. Lo que se intenta regular es el quehacer profesional mediante el señalamiento de los criterios de acción y conducta. Sin embargo, no es lo mismo acción que conducta. Acción es una cualidad del agente o del hombre racional, mientras que una conducta es algo que se repite en el tiempo y que manifiesta regularidades. En una el cálculo racional es una condición sine qua non y en la otra es una pauta que se estabiliza y se vuelve mecánica. Accionalismo y conductismo parecen incompatibles. Pero el peso de la intención parece recaer en una visión conductista y prescriptiva cuando se afirma que el código de ética profesional es un conjunto de pautas de conducta profesional respaldadas por principios de responsabilidad. Los principios de responsabilidad constituyen el marco ético. El uso de "marcos", "contextos" y "lineamientos" parecen tener en ambos casos, tanto el estadounidense como el chileno, un carácter referencial, alusivo o limítrofe: es en este marco que las acciones pueden ser valoradas. Para el caso chileno se trata de una suerte de pinochethics: se puede elegir pero de manera restringida. El código chileno está sujeto a interpretación por parte de los evaluadores y a los caminos de la jurisprudencia para evaluar las decisiones éticas. Las tensiones entre libertad y restricción muestran el hálito del neoliberalismo en la época de Pinochet, así como las confusiones entre poderes públicos, libertades ciudadanas y reivindicación de la persona. El antropólogo aparece de este modo como un indiciado: desde el momento en que alguien viola los principios del código, debe ser sancionado.

En síntesis: el código de la AAA apela a la racionalidad electiva y a la justificación informada de las decisiones. Lo que hace eficiente la norma no es la prescripción, sino el juicio fundado. Además, se prevé una ética de consumo para orientar los juicios y educar la sensibilidad de juicio de los agremiados. La racionalidad electiva, empero, no tiene respuesta para algunos problemas: 1) dilema del caeteris paribus, es decir, la imposibilidad de contar con una certeza basada en información completa; 2) la homologación de los contextos por el antropólogo, como si éste poseyera visión de paralaje (Enciclopedia Hispánica, 1999: 229), es decir, la posibilidad de integrar varias perspectivas relativas a la observación de un mismo tópico desde posiciones distintas y alejadas entre sí. Las asimetrías de poder que surgen del modelo de la racionalidad electiva son elocuentes: ¿quién es el otro?, ¿hay principios de adecuación intermedios para los partícipes de la relación "antropológica"? El antropólogo debe resguardar la reputación de la disciplina que representa y a sí mismo, justificando sus elecciones. Los problemas éticos se atenúan mediante el consentimiento "informado". Es necesario recordar aquí que la idea de "consentimiento informado" proviene de la antropología médica y se basa en una relación informada de los objetivos de la investigación antropológica que habrán de ser el eje de las interacciones entre etnógrafos y colaboradores en terreno (Aull, 1999: 46), pero deja fuera lo contingente o los efectos no deseados de la acción. ¿Cuál sería la justificación última del proceder antropológico? No hay respuesta. Por su parte, el código chileno es más bien prescriptivo que electivo: el juicio no depende de la 
racionalidad de los actores sino del incumplimiento de valores y responsabilidades que son juzgados por un comité de evaluación que emula procedimientos de jurisprudencia.

\section{OPERADORES NORMATIVOS}

En el caso estadounidense se usa la palabra "should" para sugerir lo que se "debe" o "debería" hacer, mientras que "must" expresa mayor obligación, es decir lo que se "tiene" que hacer. Hay pasajes de texto donde se intercalan ambos operadores normativos, lo que introduce un efecto de reforzamiento de la obligatoriedad. En este sentido, una diferencia radical entre el código estadounidense y el chileno es que el primero tiene un efecto performativo, mientras que el segundo posee un carácter autoritario. El primero es un código educativo que promueve en el antropólogo un papel como agente secularizador de los derechos y de ampliación de lo público, así como de resolutor de los problemas de interdependencia entre sistemas culturales. El otro código se cierra sobre sí mismo: regula a sus agremiados y los obliga a cumplir los preceptos.

En el código de la AAA el antropólogo debe establecer vínculos con las fuentes que alientan la investigación y/o producción del conocimiento antropológico, así como con las fuentes de donde se obtiene la información. El código propone como mecanismo de transparencia y regulación ética de la producción de conocimiento antropológico el "consentimiento informado" de las partes. Los oficiantes de antropología deben difundir sus hallazgos antropológicos y entrenar a sus dependientes en el manejo ético de la investigación en campo, ilustrando su aplicación in situ, o por medio de estudios de caso. En síntesis, el operador normativo "should" - debería, se debe - intenta regular la cadena productiva del conocimiento antropológico, tomando como ego al antropólogo en sus diversas interacciones con agencias de financiamiento público, privado o académico, resguardando la ética de la disciplina. Por último, es deber del antropólogo difundir la información y cuidarse de falsear datos que desvirtúen el carácter de cientificidad de la disciplina.

El código chileno sitúa al antropólogo como responsable de conducirse de manera correcta hacia sus pares - colegas, colaboradores y pares académicos en general-, dependientes - alumnos y colaboradores docentes - y patrocinadores - instituciones académicas y de investigación, agencias de financiamiento- - Las responsabilidades personales son de tipo académico - diseño y realización de la investigación- y civil - defensa de causas y derechos civiles-. La posición de ego dentro de los operadores normativos es diferente al caso estadounidense. Mientras este último propone un esquema transaccional entre agencias e informantes, en el caso chileno las obligaciones o "deberes" del antropólogo se valoran o juzgan en función de los depositarios de sus actos.

\section{DERECHOSY OBLIGACIONES}

El código de la AAA no enuncia los derechos del antropólogo, sólo se refiere a otros códigos en los que se sanciona específicamente sobre ellos: Universal Declaration of Human Rigths, United Nations Convention on the Elimination of All Forms of Discrimination Against Women, United Nations Convention on the Rigths of the Child, Forthcoming United Nations Declaration on Rigths of Indigenous Peoples. La remisión a las fuentes sobre derechos compele al lector a ejercer la intertextualidad. Este acto se puede leer de diversas formas: a) como ampliación y complemento de la información, y b) como un deslizamiento del tema ético hacia otro marco de sentido, bajo el entendido de que el código observa sus propias limitaciones para la regulación ética de algo más que una profesión. La primera es responsabilidad del antropólogo y la segunda implica el carácter autorreferencial del código. 
Para el cónclave chileno, el código se define como "principios de responsabilidad" que expresan "Derechos y Deberes de los antropólogos". La doble mayúscula de la $D$ supone la búsqueda de un equilibrio. El antropólogo puede ejercer sus derechos como ciudadano. Sin embargo, hay tensiones entre derechos y deberes según cambie la posición del antropólogo: unas veces aparece como subordinado de las poblaciones que estudia, otras como defensor de las causas civiles de las mismas, y por último como ciudadano. En cada esfera de participación el antropólogo es una figura pública obligada a desarrollar una visión "gestalt" de la realidad y también sujeto a los dilemas del pluralismo ético. Las divergencias de contexto habilitan al antropólogo como agente de secularización de valores liberales y de ampliación de los derechos ciudadanos. Si los derechos son universales y el antropólogo debe subordinar sus derechos a los de la población que estudia, entonces el código ético de Chile se ha resquebrajado:

Los derechos de los antropólogos deben estar subordinados a los derechos de las poblaciones objeto de investigación y tienen como contrapartida las responsabilidades inherentes al ejercicio de la actividad científica.

Más allá de las restricciones de los excesos en que puede incurrir el antropólogo al violentar los derechos de las comunidades o poblaciones, éste debe ejercer derechos, y es aquí donde el código chileno parece haber surcado los límites de su jurisdicción. Los derechos aluden al ejercicio pleno de la libertad de acceso a la información y a las poblaciones, lo mismo que al reconocimiento de la autoría del antropólogo en la producción y difusión de datos. La

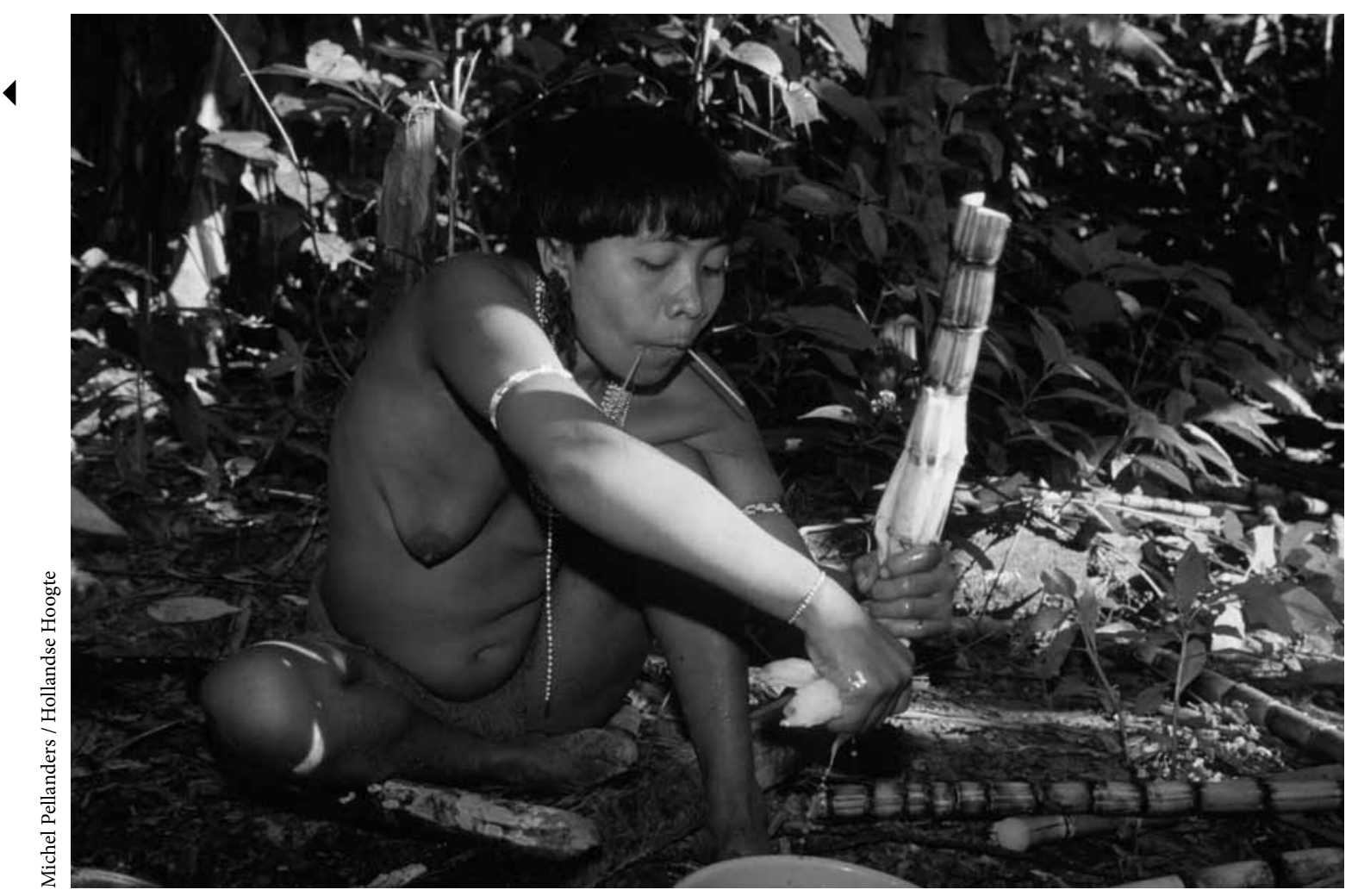

Mujer yanomami hace jugo de caña. Tootobi, Roraima, Brasil, 1996. 
mordaza epistemológica impuesta por el régimen dictatorial a las ciencias sociales y humanas que ha limitado la libertad de expresión en el pasado histórico social de Chile debe superarse en el presente por medio de los derechos de acceso a la información y a las poblaciones, así como a partir de la publicación de los resultados y el respeto a la privacidad. Mientras el código estadounidense limita los excesos en el manejo, la producción y la difusión de datos, en el caso chileno aún pesan los grilletes epistemológicos que limitan el acceso a la información.

\section{RESPONSABILIDADES}

En el caso de la AAA los deberes están aglutinados en torno a un catálogo de responsabilidades que funcionan como categorías: sólo se puede ser responsable hacia o ante alguien. El antropólogo es hecho responsable en la producción, manejo y difusión del conocimiento antropológico. También se le adjudica la responsabilidad de sortear y enfrentar las dificultades derivadas de conflictos de valores. Es responsable asimismo de difundir la información, actualizarse, dirimir controversias entre sus propios lineamientos y los contextos de producción de los saberes antropológicos. Por su parte, el código chileno propone un uso más genérico de "responsabilidad", como "principios éticos" o "pautas de conducta profesional". Los principios de responsabilidad no son exhaustivos y dejan margen razonable para la interpretación. No obstante, lo prescriptivo se impone al obrar cuando el código chileno dice emular los procedimientos de jurisprudencia para evaluar la conducta de un antropólogo que es denunciado por contravenir los principios de responsabilidad. A diferencia del uso del sustantivo "responsable" en el caso estadounidense, acompañado de mandatos - debe de, tiene que-, el caso chileno alude al término más bien genérico y universal de la "responsabilidad".

En suma, el código de la AAA posee un carácter pragmático y el código chileno es más bien prescriptivo. Uno alude al exceso de información y el otro a la necesidad de ampliar sus límites. Uno promueve el monitoreo y la difusión del código ético y el otro su aplicación y evaluación a través del juicio de un comité autorizado. Uno es de sentido práctico y el otro de sentido normativo. El primero negocia y obtiene el consentimiento de la información vinculante entre el antropólogo y los demás y el segundo exige garantías para el acceso y difusión o no de la información. Uno se expresa y al otro le pesa el contexto para expresarse. Ambos surgen en contextos neoliberales y apuestan a diversas restricciones sobre la libertad de producir, difundir y controlar el proceso productivo de la información y los saberes antropológicos. Al liberalizarse la economía se liberalizaron los procesos políticos. Con ello se amplía o se restringe la esfera pública: al surcar los espacios porosos de las fronteras culturales, el antropólogo como figura cívica se ha convertido, quizá sin advertirlo, en un agente secular de la ampliación de los derechos cívicos, y cuando se ha percatado ha adoptado el papel o bien de un ciudadano, de un conformista, de un luchador social o de facilitador de las empresas colonial y neocoloniales. Nadie puede estar más allá del bien y del mal. Los detractores de la antropología solamente han expuesto la reputación de la disciplina. El juicio a la antropología nos recuerda el juicio a Murena, quien es llamado a cuentas por la acusación de haber incurrido en fraude electoral. A diferencia de los patricios, Murena se ve obligado a defender su honor, pues no tiene la virtud que otorga el reconocimiento social de procedencia. A lo sumo cuenta con un mecenas que reconoce sus atributos intelectuales y políticos. Será la primera vez que se da testimonio de que un individuo debe demostrar públicamente su inocencia ante un tribunal, el cual dictaminará sobre el honor o la deshonra del indiciado y consecuentemente sobre su aceptación o rechazo (Cicerón, 1984). Por analogía, cuando el antropólogo es tratado como indiciado por los medios de comunicación, entre otros, lo que se juega es la imagen de la antropología, y no sólo la reputación de uno de sus cónclaves. 


\section{CODIFICACIÓN INTELIGENTE DE LA ÉTICA ANTROPOLÓGICA}

Comenzaremos por el reconocimiento de los límites encontrados en los códigos de ética analizados. La ética del consentimiento de la información no resuelve dos problemas: 1) no se tiene información completa y eso limita la racionalidad electiva y la idea de la decisión mejor fundada, y 2) tampoco se tiene control sobre los cauces no deseados de la acción. Por su parte, el modelo de experto y juez, adjudicala ética, nola promueve. Seguir prescripciones, en este caso, anula la capacidad de juicio y el sentido del obrar éticamente. Ante estos problemas, el alcance normativo de los códigos analizados es insuficiente. Como respuesta a estas limitantes se ha propuesto una ética de la negociación y colaboración entre expertos y audiencias e incluso de negociación del trabajo de campo (Meskell y Peels, 2005: 3). Por nuestra parte, avanzaremos en la evaluación de las relaciones entre acciones y valores tomando copor los trabajos etnográficos entre los yanomami, de manera que podamos ir modelando una codificación inteligente de la ética antropológica. Los yanomami nos recuerdan el fin de la historia introducido por H. G. Wells (2002) en su obra de 1895, La máquina del tiempo. Wells anticipa el sentido limítrofe de la modernidad: ¿el viajero en el tiempo tiene derecho a intervenir en el cauce de los acontecimientos?, ¿si interviene en ellos, modificará la historia de manera grave? Ilustraremos este dilema con el siguiente ejemplo. Los yanomami habitan en el Amazonas en la región del Orinoco, tanto en la parte venezolana como en la brasileña. Viven en shabonos o aldeas comunales y la vida social se organiza bajo los mismos principios usados por otras tribus: "relaciones de parentesco, descendencia de los ancestros, intercambios matrimoniales entre grupos de parentesco descendentes" (Chagnon, 1983: 6). Además, son comandados por jefes carismáticos, quienes asumen la responsabilidad de establecer relaciones con otros pueblos. Aunque pueden

devenir autócratas, son "grandiosos" entre pares. Inclusive:

Ellos son simultáneamente pacificadores y valientes guerreros. Los pacificadores frecuentemente requieren el uso de la fuerza, e incluso muchos jefes han adquirido reputación por ser waiteri: feroces (Chagnon, 1983: 7).

El autor está ejerciendo su oficio apegado a la concepción de "ciencia objetiva". Su mirada etnográfica es de tipo organizacional y funcionalista. La fiereza a la que alude Chagnon observa una justificación hacia el final del texto, donde aparentemente se vuelve confesional:

\begin{abstract}
Yo decidí, cuando llegué por primera vez a vivir entre los yanomamö en 1964, que sus guerras eran el tópico más importante que demandaba atención etnológica, debido a que las guerras habían recibido muy poca atención de la profesión [...] El hecho es que muy pocos antropólogos han tenido la oportunidad de vivir con los nativos y estudiarlos mientras la guerra era un hecho significativo de vida entre ellos (Chagnon, 1983: 213-214).
\end{abstract}

Chagnon confiesa que al abordar temas como el de la guerra, el etnógrafo está en una situación comprometedora, pues requiere "la presentación de hechos e información que muchos de nosotros preferiría no tomar en cuenta" (Chagnon, 1983: 214). Aquí el etnógrafo parece instruirnos sobre el valor de la verdad, aunque ésta sea comprometedora. Comparados con la violencia y militancia encontradas en otras culturas, pero particularmente en "la nuestra", afirma el autor, sus colaboradores guerreros serían unos ángeles: "los yanomamö, parafraseando a Mark Twain, están mucho más cerca de los Ángeles que del Diablo" (Chagnon, 1983: 214). El texto concluye con una advertencia hacia los encargados de integrar a los yanomamö en la cultura nacional, para que lo hagan dignamente y tomen en cuenta el valor cultural. También conmina a los colegas brasileños y venezolanos a valorar a los yanomamö 
como "nuestros ancestros contemporáneos" (Chagnon, 1983: 214). Termina el viaje a través del tiempo. ¿Fue alterada la historia?

Hemos expuesto al antropólogo de la "fiereza" en sus propias palabras. Ahora realizaremos un recorrido cronológico para situar la emergencia del debate ético en torno al golpe mediático de Darkness in El Dorado (Tierney, 2000), donde se denuncia la presunta inmoralidad de Neel, Chagnon y Lizot, entre otros, quienes trabajaron en la zona del Orinoco con grupos yanomami. En 1975, el gobierno brasileño hace del conocimiento público el descubrimiento de oro en la región de los yanomami. Entre 1980 y 1987, algunos grupos mineros incursionan en la zona promoviendo conflictos socioterritoriales. El resultado: un acto genocida que acabó con 2000 integrantes de tribus yanomami (Ushiñahua, 1980). En este contexto, el antropólogo francés Jacques Lizot (1985) parece coincidir en la defensa de los derechos nativos con los salesianos, misioneros católicos. Chagnon había descrito el proceso de aculturación que comenzó en la década de 1970 por iniciativa del gobierno venezolano a través de un proyecto denominado "Codesur", la "Conquista del Sur". En el proceso "civilizatorio" participaban grupos de misioneros católicos y protestantes, quienes hacia la década de 1980 pretendían modificar algunas costumbres nativas invitando a los yanomami a cubrir su desnudez como un acto de "moralidad", pero sin éxito (Chagnon, 1983: 213). Ante la rapacidad minera, el gobierno brasileño decidió crear una reserva federal indígena en 1992, pero al año siguiente los mineros intentaron exterminar una aldea completa. Un año después, en 1994, se edita el video de Jacques Lizot, The Spirit of the Rainforest, quien para entonces había escrito un texto sobre relatos yanomami donde narra el "endocanibalismo" nativo, consistente en comer los huesos de los difuntos en una mezcla de sopa de banana (1985). En el filme se presentan tres viñetas etnográficas: por qué los yanomami practican la guerra entre aldeas, por qué practican el endocanibalismo y su exposición a las epidemias provocadas por enfermedades "occidentales". Las viñetas etnográficas del video confirman imágenes de violencia, incurren en la violación del principio de secrecía sobre los muertos, exhiben el impacto de enfermedades occidentales en la salud de los nativos y muestran la presencia de elementos interculturales. The Spirit of The Rainforest cierra con una plegaria a favor de los nativos: necesitan de "nuestra" ayuda médica.

Más tarde, en 1998, la presidenta de la Asociación Brasileña de Antropología envía una carta a la dirección de la AAA, y aunque no recibe respuesta, fue publicada una nota en Anthropology Today. En dicha carta se demanda la investigación de los juicios infundados de Chagnon en torno a la supuesta "fiereza" de los yanomami por influir en las percepciones sociales de manera negativa. La denuncia no sólo es por falta de objetividad, sino por falta de responsabilidad social al haber difundido estigmas (Ramos, 2004). Dos años después, la publicación de Darkness in El Dorado (Tierney, 2000) provoca un colapso en "las relaciones públicas" de la antropología, según Jane Hill (Pels, 2005: 70), vocera de la AAA ante el escandaloso suceso. El periodista Patrick Tierney señala al científico Neel y al antropólogo Chagnon como responsables de ignominia ante la posibilidad de atenuar los efectos de una epidemia que diezmó a la población yanomami. Supuestamente, Neel introdujo experimentos genéticos sin consentimiento de las poblaciones. Otros antropólogos también son señalados, como Jacques Lizot, a quien se atribuye haber mantenido relaciones sexuales con varios muchachos de tribus yanomami, aunque también se le reconoce como defensor de los derechos de los nativos. Por su parte, a Good, alumno de Chagnon, quien terminara distanciado de su mentor, se le adjudica haber surcado las distancias entre antropólogo y nativos al haberse casado con un yanomami, de quien habría de divorciarse un par de años después (Borofsky, 2004: 21).

La controversia llevó al establecimiento de una comisión que habría de responder las diatribas. Los medios catalogaron al antropólogo como 
problemático y caricaturizaron a la disciplina como "la antropología en el corazón de las tinieblas". Estas denuncias llevaron al replanteamiento público de la antropología y a reconsiderar las relaciones entre ciencia, ética y ejercicio profesional. Sin duda un referente obligado para tomar decisiones éticas en la controversia expuesta fue el código de ética de la AAA. A continuación expondré mi posición sobre principios y ética profesional en el ejercicio de la antropología, para continuar con un caso que nos permita ilustrar un modelo evaluativo de carácter deóntico.

\section{PRINCIPIOSY ÉTICA PROFESIONAL}

Se pueden adoptar dos posturas en torno al problema de las conexiones entre ejercicio profesional y códigos o principios éticos en antropología. La primera consiste en aseverar que la lógica de la investigación socioantropológica es independiente de los códigos o valores que se le imputan en la búsqueda de la verdad y la objetividad. Esta primera posición es compartida por los defensores de una concepción de realidad que es independiente de la volición y las preferencias personales del investigador (Bunge, 2009: 3449; Wilson, 2004), aunque elude el compromiso relacional e intersubjetivo con la producción de conocimiento de segundo orden. La posición opuesta afirma que el investigador constituye parte del horizonte de comprensión del objeto mismo que estudia y para acceder al núcleo de sentido de los actos hace valer la solidaridad de una comunidad de habla y la textualización de la cultura (Vattimo, 2010: 146; Geertz, 1994: 45). Sin embargo, en cualquiera de las dos posiciones, ya sea que se defienda el distanciamiento o la familiarización con el objeto de estudio, es importante vincular el acto de "profesar" una "profesión" con los principios que orientan y explican su fundamento.

El principialismo propugna la idea de que sin una jerarquización de valores no se puede evaluar el rendimiento, en este caso, de una profesión. Para decirlo de otra manera: los hechos, bien que hablemos de gradaciones, entre "hechos brutos" $y$ "menos brutos", solamente son susceptibles de ser contrastados de iure y de facto (Anscombe, 2006: 36), si y sólo si apelamos a una escala de valores. Sin principios que permitan discernir cuándo ha habido un "buen desempeño" no sería posible discriminar entre un buen trabajo - como aquel que deja satisfecho, en diversos grados, a quien lo desempeña, a sus pares $y$ al destinatario de sus obras- y su respectiva resonancia como desempeño ético - como la actualización de la relación fundante de la profesión-. Es en este sentido que hablamos aquí de clave y cónclave. En otros términos, entre los profesantes y una profesión hay códigos vinculantes que fundan y fundamentan esta relación. Esta posición no significa que los códigos o principios éticos de una profesión se reduzcan a una gramática normativa, sino que más bien los principios que apelan a escalas de valores suponen una doble concepción de la ética profesional, en el sentido complementario y flexible que propone Agnes Heller (2008: 22) a propósito de lo que denomina "los dos pilares de la ética moderna”: el personalismo y las visiones constitutivas de la sociedad. La dualidad fundacionalfundante de los principios éticos presupone que en el horizonte de la primera persona - yo- alguien elige ser "buena persona", mientras que en el horizonte de la tercera persona del plural - nosotros- las virtudes cívicas son sancionadas en función de la relación de membresía que se establece con los otros y que cristaliza en lo que habitualmente designamos como Estado de derecho. Los principios que orientan los modos de hacer del antropólogo en terreno no son normas que anteceden a las acciones, sino solamente un marco de sentido bajo el cual los aspectos constitutivos del obrar antropológico cobran sentido. En consecuencia, se trata de principios que orientan la acción, pero que no necesariamente la rigen. En síntesis, podemos definir un código ético profesional como un marco de sentido que apela a principios que orientan los 
modos de hacer del profesionista, mismos que se actualizan o recrean en la perspectiva de la primera persona.

\section{LÓGICA DEÓNTICAY RESPONSABILIDAD}

A diferencia de otros sistemas normativos, la lógica deóntica presupone las normas. Von Wrigth (2001) ha intentado eludir el compromiso de las normas con su estructura sintáctica, porque éstas no se reducen a signos - sintaxis-, y tampoco a la sola enunciación — pragmática-. Hay normas, afirma Von Wright, que resisten la lingüistización. De modo que las normas no son proposiciones ni enunciados. Las implicaciones de esta concepción deóntica recaen en el plano de las acciones: no son obligatorias en sí mismas. Veremos a continuación cómo opera la lógica deóntica al distinguir entre tipos de acción y estado de cosas. Si una acción consiste en producir o prevenir cambios, entonces será necesario registrar el cambio. Consecuentemente, afirma Von Wrigth: "una lógica de la acción presupone una lógica del cambio" (Von Wrigth, 1998: 39). Por cambio entenderemos la transformación de estados, es decir, cuando un estado de cosas cesa o empieza a existir. También se da el caso de que un estado de cosas continúe, es decir, que permanezca sin cambiar. De un estado de cosas a otro podemos hablar de un tiempo genérico. Habría que determinar si lo que un antropólogo hace se traduce en cambios en el estado de cosas cuyas implicaciones repercutan en el orden de los juicios valorativos, a saber: acciones positivas o acciones omisivas, y preguntar enseguida por qué. Apelaremos a tres operadores deónticos que modalizan los cauces de acción: $P$, posible; $I$, imposible, y $N$, necesaria. Tomando en cuenta los modalizadores, ilustraremos la lógica deóntica de Von Wrigth con el caso Lizot.

Hemos enunciado que los detractores de Jacques Lizot lo juzgan y lo reconocen por dos cosas (Borofsky, 2004): por mantener relaciones sexuales con algunos jóvenes yanomami y por erigirse en uno de los defensores más enconados de los derechos humanos de los yanomami. La tensión entre deber y poder en el caso Lizot nos permitirá analizar la relación entre normas y valores que subyacen al estado de cosas. La relación entre lo que hacemos y lo que podemos hacer ante una situación, en alguna circunstancia y dentro de un contexto, sólo es posible por un estado de cosas. Más allá de la elección de los cauces de acción o del plano axiológico que guía los actos del sujeto, debe haber condiciones de posibilidad que habiliten una acción. De acuerdo con la lógica deóntica, un estado de cosas haría: a) posible; b) imposible, o c) necesaria una acción, ya sea de manera legal o física. Cada acción implica una relación entre normas y valores, es decir, una relación evaluativa entre lo que se debe y se puede hacer. Cada índice puede acompañarse de una proposición con el fin de ejemplificar los cauces de acción:

a.1) Si bien es cierto que no parece haber nada ni nadie entre los yanomami que se oponga a que Lizot establezca relaciones sexuales con los nativos, no se deduce de ello que el antropólogo deba cruzar la brecha cultural y contextual que lo distingue de sus pares. Cuando el antropólogo surca esa brecha hace violencia del otro, porque asume que forma parte de un bando. Sin duda, al haber intimado con la población que estudia, Lizot debe elegir entre seguir siendo antropólogo o asumirse como uno más entre los nativos. Por consecuencia, el hecho de actuar en un contexto permisible no significa que así deba ser. La decisión es individual y valorativa: es posible, se puede, pero el sujeto evalúa si se debe o no se debe actuar de la manera como lo hizo.

b.1) Si Lizot es quien proporcionó rifles y dinero a los yanomami para que colaboraran en la escenificación de un ritual de guerra, como puede llegar a inferirse del video que hemos citado, entonces se ha incurrido en la transgresión del entorno. Sin embargo, en una secuencia se puede apreciar que el chamán de la aldea pide 
expresamente dinero y utensilios al etnógrafo, por lo que podríamos decir que Lizot se condujo de esa manera en relación con las exigencias de sus pares. Cuando los hombres son reducidos a un medio se viola el principio kantiano de concebir al hombre como un fin. Se hace violencia del Otro, aun cuando el Otro contribuya y establezca condiciones de posibilidad para ello.

c.1) Lizot defiende los derechos de los yanomami, pero ¿por qué es necesario defender los derechos de los yanomami? Porque se trata de la defensa de su integridad. Lizot evalúa lo que se debe y se puede hacer para resguardar la integridad de sus colaboradores nativos. La relación entre deber y poder es más fuerte cuando surgen de un estado de necesidad.

Todo acto susceptible de ser evaluado debe estar acompañado de valores. Sin embargo, el hecho de que la racionalidad de los actos esté limitada por la responsabilidad en la transformación de un estado de cosas; por otra parte, se puede actuar sin intención y ser responsable de lo acontecido. Las variaciones que tienen lugar para explicar cuando alguien es o no responsable de sus actos y de las implicaciones de los mismos, propone Williams, nos llevan a reconocer cuatro elementos constitutivos de cualquier concepción de responsabilidad: causa, intención, estado y respuesta.

En todas partes, los seres humanos actúan y sus acciones hacen que pasen cosas, unas veces de manera intencional y otras no; en todas partes, en ocasiones el agente $\mathrm{u}$ otros sufren por lo ocurrido, o ambos lo lamentan o lo deploran; y cuando esto ocurre tal vez se exija que el agente responda de algún modo, y esta exigencia puede venir de él mismo, de otros o de ambos (Williams, 2006: 175). En consecuencia, el interés por la responsabilidad generalmente se dirige hacia las intenciones del agente. No obstante, como lo demuestra Williams, puede ocurrir que se presente lo que en el derecho moderno se concibe como "responsabilidad sin causalidad", es decir, cuando alguien es hecho responsable por los actos de otros, que dependen en lo fundamental de un representante. Por su parte, Roman Ingarden propone una ética multidimensional de la responsabilidad que no elude el tema de la jerarquización de valores. La idea heurística que retomaremos de Ingarden afirma que no es posible evaluar éticamente las acciones sin partir de valores. Su perspectiva nos colocará en posición de avanzar en la sistematización de las condiciones de posibilidad que permiten evaluar normativamente la relación entre actos y operadores deónticos. De acuerdo con Ingarden (2001), la responsabilidad observa cuatro concreciones: 1) se tiene la responsabilidad de algo; 2) se asume la responsabilidad de algo; 3 ) se es hecho responsable de algo, y 4) se obra de manera responsable. Cada concreción de responsabilidad observa gradaciones sobre valores, conciencia de actos, resultado de los actos; además, incluye la posibilidad de la reparación o la venganza, es decir, la posibilidad de actuar responsablemente enmendando el ce que un acto es causa de algo, por lo que se asume 
daño, o bien actuar de modo irresponsable. Si nos centramos sólo en las consecuencias de la acción, es claro que no todo acto redunda en un dilema moral, puesto que hay responsabilidad sin causalidad y consecuencias no deseadas de la acción, como reconoce Bernard Williams. En esta dirección, Ingarden introduce la relación entre temporalidad y responsabilidad, estableciendo una condición de posibilidad:

El agente sólo es responsable de su acción y de su resultado cuando se han hecho realidad. Luego pertenecen al pasado. Pero, si no existe en ningún sentido la acción pasada - lo "hecho"-, entonces no queda nada de lo que el agente pueda ser responsable. También los valores realizados o aniquilados por la acción dejan de ser, así como su realización o aniquilación (Ingarden, 2001: 96).

Sin el recuerdo de un acto y de sus consecuencias nocivas no se puede asumir la responsabilidad y tampoco responsabilizar a alguien. Pero además, si el recuerdo no se corresponde con nada existente, la responsabilidad adjudicada sería infundada. No obstante, situar la responsabilidad en términos causales por medio de inferencias sobre lo acontecido o recordado, o mediante lo esperado, como mera proyección de las expectativas que se generan entre quien obra y los destinatarios de sus actos, sería reducir los valores a un emergente y lábil consecuencialismo. Los valores poseen una temporalidad, y es justamente a través de las acciones que se emprenden que se realizan o se destruyen esos valores. Cuando alguien es hecho responsable, en ese momento ya no existen los valores destruidos o producidos por él. La temporalidad de los valores se ejerce en el momento, pero en cuanto suponemos que un acto que transforma un estado de cosas produce o destruye valores, entonces partimos de principios o jerarquías de valores. Solamente así explicaríamos cuando alguien ha producido o destruido valores. En consecuencia, sin principios no es posible discutir acerca de la responsabilidad de los agentes en la transformación de los estados de cosas. Vamos a ilustrar de manera breve el mismo caso de Lizot con las dimensiones de responsabilidad propuestas por Ingarden:

a) Responsabilidad tipo 1 (RT1). Uno tiene la responsabilidad de algo. Uno es responsable de algo. Lizot es responsable de haber denunciado la muerte de algunos nativos yanomami por el efecto de contacto con enfermedades "occidentales" para las cuales no han desarrollado defensas de inmunidad. Esta dimensión de responsabilidad es independiente de que el sujeto piense o no que es responsable.

b) Responsabilidad tipo 2 (RT2). Uno asume la responsabilidad de algo. Lizot asume haber obrado de manera determinada dentro de un cauce de acciones posibles. Su justificación puede apelar a condiciones de necesidad, pero no a las de permisibilidad.

c) Responsabilidad tipo 3 (RT3). Uno es hecho responsable de algo. Lizot es acusado por segundas o terceras personas de haber actuado de una determinada manera, bien que Lizot asuma o no la responsabilidad. La reputación del antropólogo es puesta entre paréntesis. Para restituir personalidad a su oficio deberá reconstruir la axiología de sus actos. La valoración de los mismos por el "indiciado" tendrá por objetivo o bien el reconocimiento de su responsabilidad o bien la justificación de sus actos mediante argumentos. Pero como se trata de una imputación, deberá refutar o reconocer. En este ámbito se juega y se actualiza la imagen pública del antropólogo como representante de la antropología.

d) Responsabilidad tipo 4 (RT4). Uno obra responsablemente. Desde el momento en que Lizot decide defender los derechos humanos y establecer vínculos amorosos con sus pares nativos, la relación entre lo que se puede hacer y lo que se debe hacer está sujeta a una evaluación de las condiciones de posibilidad. Obrar responsablemente significaría que el antropólogo ha debido derivar el sentido de sus actos de un estado de necesidad, 
no de permisibilidad. Por esta razón, podríamos consentir que la primera decisión es razonable, mientras que la segunda es producto de la voluntad y del deseo. La controversia surge de haber traspasado los límites entre la investidura profesional y la personal. Cuando ambas se enfrentan, los cuestionamientos no distinguen entre esfera pública y esfera privada, puesto que alguien se ha valido de la investidura para la realización de sus deseos.

Las cuatro dimensiones de la responsabilidad desafían la concepción ética que anticipa el sentido de las acciones. No se puede evaluar el desempeño ético de un profesionista por lo que pensaba antes de proceder de alguna u otra forma. Derivar el sentido de responsabilidad de la consecución o asentimiento de las personas que forman parte del contrato antropológico no tiene sentido de cara al desarrollo del proceso etnográfico. En el camino es claro que el antropólogo, así como los depositarios de sus actos, pueden contravenir los términos del contrato. Si el antropólogo consigue hace valer una visión de paralaje, se convertiría en un árbitro neutral para resolver las controversias éticas que surjan de puntos de vista encontrados. Pero si su tendencia como árbitro se inclina hacia alguna de las partes en conflicto, entonces, lejos de codificar inteligentemente las relaciones éticas en cada una de las fases del continuum anthropologicum, compromete sus hallazgos para el acrecentamiento de las asimetrías de poder. A continuación situaré la dimensión axiológica y la fenomenología de la responsabilidad dentro de un continuo temporal o cadena productiva del conocimiento antropológico.

El continuum antropológico está conformado por tres momentos relacionales con la manera de obrar del antropólogo (véase tabla 1). En el principio del continuum, ex ante, se sabe lo que se quiere hacer. El antropólogo, siguiendo el modelo estadounidense, negocia y consensa los objetivos de la investigación apelando al principio democrático de la transparencia en el uso de la información. Sin embargo, se trata de un simulacro de caeteris paribus. Al prever los usos de la información y el derecho a la transparencia, se fijan los términos del convenio de trabajo antropológico. El antropólogo establece las condiciones de posibilidad dentro de las cuales habrá de desarrollar los objetivos de investigación, por lo que la justificación última de su proceder se basa en un principio de racionalidad electiva: los actos podrán justificarse tomando como punto de partida el consentimiento de la información.

La siguiente dimensión del continuum es lo que sucede durante el proceso de trabajo. En situación, el etnógrafo debe apegarse a rectitud y patentar su compromiso con la verdad, reconocer sus limitaciones y respetar los valores locales. Debe rechazar la injusticia en el momento en que se requiera. En esta etapa surgen controversias entre los límites de la persona y el profesionista. Por último, en la dimensión ex-post factum el antropólogo y los depositarios de sus actos, distanciados temporalmente de las acciones que han tenido lugar, evalúan lo que se hizo. Intentar juzgar a los actores en función de lo que han dicho o han hecho es una forma de descontextualización de la relación entre el estado de cosas y lo que se puede o debe hacer. Pero como los procesos sociales se desenvuelven en el tiempo, algunos actos pueden tener consecuencias en el futuro o no ser visibles en el momento mismo en que ocurren. Ninguno de los momentos del continuum por sí mismo nos garantiza la posibilidad de evaluar éticamente el desempeño de la antropología. Para completar la codificación propongo realizar una síntesis entre las dimensiones enunciadas: axiología, responsabilidad y continuum antropológico.

Cuando apelamos a RT1, toda justificación de las decisiones de obrar éticamente son posibilitadas por el estado de cosas y su evaluación sólo puede ser temporalmente ex-post factum. El que sea posible conducirse de una cierta manera no implica la simetría entre lo posible y lo deseable. Sin embargo, cuando el actuar responsablemente desde una óptica universal es posible y necesario, entonces el antropólogo ha actuado como "debe ser". En el 
Tabla 1. Proceso de producción del conocimiento antropológico Continuum anthropologicum

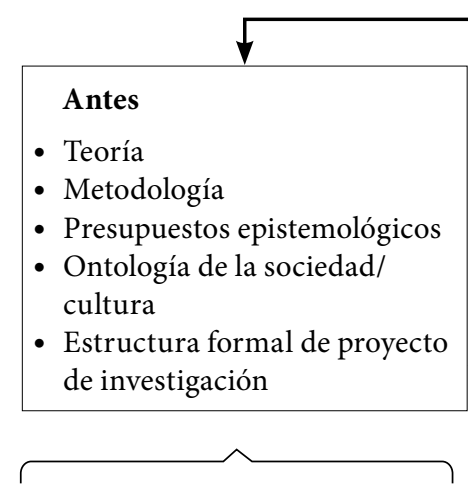

Ex-ante

Fuentes de la investigación:

a) Financiamiento público. Agenda de investigación fijada por el interés público.

b) Financiamiento privado. Agenda de investigación fijada por el interés privado.

c) Cofinanciamiento. Agenda de investigación fijada por la convergencia de intereses públicos y privados.

d) Autofinanciamiento. Agenda de investigación fijada por amor al arte (idealmente).
El contexto y el dato son construidos relacionalmente

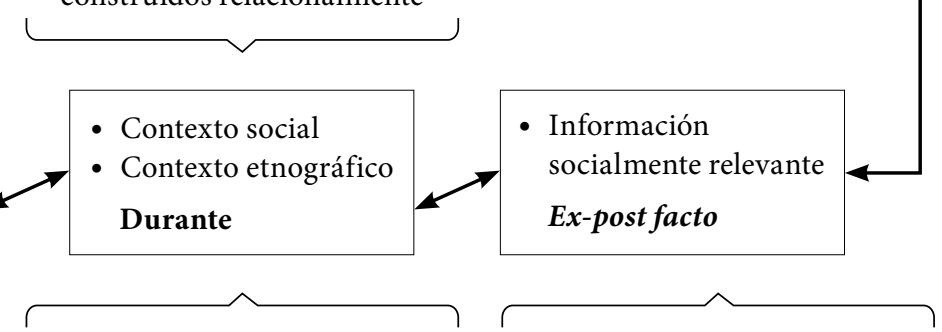

El contexto social es un marco de sentido (condición de posibilidad). El dato es producto de las descripciones "objetivas" y de la observación de regularidades.
Usos de la información. Se escribe para un público vasto o restringido. El texto se emancipa de la intención del autor. Límites de la interpretación. Consecuencias no deseadas de la acción.

Consecuencias intencionales.

Fuente: Elaboración propia (2011).

siguiente caso, RT2, es el antropólogo mismo quien asume la responsabilidad de sus actos. Por consecuencia, es posible que éste sea uno de los escenarios donde se revelen disputas entre lo permisible y lo justificable. Cuando se conjuga la responsabilidad asumida en primera persona con el estado de necesidad, lo que tiene lugar es la autorrealización. El cónclave actualiza la imagen de la antropología y muestra la eficacia del código. El tercer caso, RT3, se refiere a la adjudicación de responsabilidad. Independientemente del plano de la autoconciencia, alguien más responsabiliza al artífice de la primera persona. Dado que el estado de cosas abre la posibilidad para actuar de una manera u otra, el antropólogo en este plano enfrentaría juegos de reputación o refutación para demostrar que lo que hizo era lo más viable. La controversia muestra límites al código, pero al hacerlo señala otros caminos de codificación. Sin embargo, si el contexto demanda que el acto seguido sea habilitado por el estado de necesidad, entonces la adjudicación o imputación de haber obrado mal deja de tener sentido. Por último, RT4: cuando el antropólogo obra responsablemente ha logrado control de alteridad, responsabilidad en la construcción y abordaje del proceso socioantropológico, y es consecuente con la elección de cauces de acción y sus implicaciones. Esto sucede teóricamente en cada una de las 
Tabla 2. Dimensiones de la responsabilidad enunciadas (resumen)

\begin{tabular}{|c|c|c|c|c|}
\hline Responsabilidad & Posible & Imposible & Necesario & Continuum \\
\hline RT1 & $\begin{array}{l}\text { El antropólogo } \\
\text { es responsable en } \\
\text { términos universales. } \\
\text { Lo permisible no } \\
\text { necesariamente } \\
\text { justifica lo deseable. }\end{array}$ & & $\begin{array}{l}\text { El antropólogo } \\
\text { es responsable en } \\
\text { términos universa- } \\
\text { les de actuar como } \\
\text { debe ser. }\end{array}$ & $\begin{array}{l}\text { Justificación ex-post } \\
\text { factum }\end{array}$ \\
\hline RT2 & $\begin{array}{l}\text { El antropólogo asume } \\
\text { su responsabilidad } \\
\text { por haber obrado } \\
\text { de una determinada } \\
\text { manera. Tensión } \\
\text { entre lo permisible } \\
\text { y lo justificable. }\end{array}$ & & $\begin{array}{l}\text { Conjunción entre } \\
\text { la responsabilidad } \\
\text { en primera persona } \\
\text { y el deber ser. Cumple } \\
\text { con el principio ético } \\
\text { de autorrealización. }\end{array}$ & Ex-post factum \\
\hline RT3 & $\begin{array}{l}\text { Adjudicación de } \\
\text { responsabilidad } \\
\text { en condiciones de } \\
\text { posibilidad. Juegos } \\
\text { de reputación/ } \\
\text { refutación. }\end{array}$ & $\begin{array}{l}\text { El argumento } \\
\text { de imposibilidad } \\
\text { desestimaría } \\
\text { la adjudicación } \\
\text { de responsabilidad } \\
\text { por terceros. }\end{array}$ & & Ex-post factum \\
\hline RT4 & $\begin{array}{l}\text { El antropólogo obra } \\
\text { responsablemente. }\end{array}$ & & $\begin{array}{l}\text { Relación intrínseca } \\
\text { entre principios éticos } \\
\text { y obrar. }\end{array}$ & $\begin{array}{l}\text { Ex-ante } \\
\text { Durante } \\
\text { Ex-post factum }\end{array}$ \\
\hline
\end{tabular}

etapas del continuum, lo cual supone que la antropología ha alcanzado el ejercicio pleno de la autorreflexividad.

\section{CONCLUSIÓN}

La producción del conocimiento antropológico observa diversas fases que se retroalimentan y que configuran áreas de interés en las que convergen hechos y valores que orientan la discusión sobre fenómenos "morales". Antes de emprender una investigación el antropólogo debe preguntarse para quién trabaja y cuál será su aporte para la comprensión del fenómeno que se investiga, así como sus implicaciones prácticas. Los criterios establecidos como parámetros que permiten juzgar la pertinencia de una propuesta de investigación consisten en que el profesionista esté actualizado en los temas que pretende investigar, que conozca las dinámicas regionales de la zona de estudio, las tendencias estadísticas básicas y concretas. La formulación de un problema de investigación se desprende de una posición crítica, reflexiva, informada y argumentada. Según los imperativos de la teoría y la metodología, lo que se conciba como evidencia empírica y la forma de construirla tendrá implicaciones no solamente ontológicas o epistemológicas, sino también éticas. En cada una de estas posibilidades subyacen ideales sociales cuyo valor cognoscitivo se corresponde con valores morales.

Dado que el antropólogo produce información socialmente relevante, no se pueden eludir las implicaciones éticas acerca de las repercusiones que puede tener un hallazgo en la esfera pública. En este contexto, el antropólogo debe asumir su responsabilidad 
dado que produce información acerca de terceros. La recepción de las obras antropológicas no tiene un destino homogéneo. Habrá múltiples lecturas de un texto que desafíen el acuerdo entre la intención del autor y el lector. La reconstrucción de lo que "quiso decir el autor" se convierte en el telón de fondo para la decisión sobre la responsabilidad social del etnógrafo ante situaciones emergentes que pudieron haberse desencadenado por la circulación de información.

La codificación ética del desempeño antropológico esbozada aquí comparte la idea de que cuando surgen controversias sobre responsabilidades abordamos la ética profesional como un fenómeno. El cumplimiento de las cuatro dimensiones de responsabilidad fortalece la relación entre principios éticos y cauces de acción. Cuando no es así debemos aprender de las dimensiones restantes para comenzar la reflexión sobre la jerarquización de valores. No podemos separar hechos y valores del estado de cosas. Cuando hablamos de la conjunción entre deber, poder y estado de necesidad es cuando descubrimos las jerarquías de valores absolutos y relativos. La lógica deóntica nos permite evaluar las transformaciones que produce el desempeño antropológico en el estado de cosas, promoviendo o destruyendo valores, e incorporando las dimensiones de responsabilidad como condición de posibilidad de los dilemas morales emergentes. Cuando el apego a la rectitud tuviese lugar, el código mismo de la antropología se habrá convertido en un emblema.

It is impossible To achieve de aim without suffering. Robert Fripp, Exposure.

\section{Referencias bibliográficas}

Anscombe, Elizabeth, 2006, "Filosofía moral moderna", en Mark Platts (comp.), Conceptos éticos fundamentales, Universidad Nacional Autónoma de México, México, pp. 27-53.
Asad, Talal, 1973, Anthropology and the Colonial Encounter, Ithaca Press, Londres.

Aull Davies, Charlotte, 1999, Reflexive Ethnography. A Guide to Researching Selves and Others, Routledge, Londres.

Borofsky, Robert, 2004, Yanomami. The Fierce Controversy and What we Can Learn From it, University of California Press, Berkeley y los Ángeles.

Bunge, Mario, 2009, Epistemología, Siglo XXI, México.

Camps, Victoria, 1992, “Presentación”, en Victoria Camps, Osvaldo Guariglia y Fernando Salmerón (eds.), Concepciones de la ética, Trotta, Madrid, pp. 11-27.

— 2005, Ética, retórica, política, Alianza Editorial, Madrid.

Chagnon, Napoleon, 1983, Yanomamö. The Fierce People, Holt, Rinehart and Winston, Inc., Chicago.

Cicerón, Marco Tulio, 1984, En defensa de Murena, Universidad Nacional Autónoma de México, México.

Clifford, James y George Marcus (eds.), 1991, Retóricas de la antropología, Júcar, Madrid.

Cortina, Adela, 2000, "Presentación. El sentido de las profesiones”, en Adela Cortina y Jesús Conill, 10 palabras clave en ética de las profesiones, Editorial Verbo Divino, Navarra, pp. 13-28.

Enciclopedia Hispánica, 1999, "Método de las paralajes", en Micropedia, vol. 2 Encyclopædia Britannica Publishers, Buenos Aires, Chicago, p. 229.

Gardner, Howard, Mihály Csíkszentmihályi y William Damon, 2002, Buen trabajo. Cuando ética y excelencia convergen, Paidós, Barcelona.

Geertz, Clifford, 1994, Conocimiento local. Ensayos sobre la interpretación de las culturas, Paidós, Barcelona.

Grupo Latinoamericano de Estudios Subalternos, 1998, "Manifiesto inaugural", en Santiago Castro-Gómez y Eduardo Mendieta (coords.), Teorías sin disciplina. Latinoamericanismo, poscolonialidad y globalización en debate, University of San Francisco, Miguel Ángel Porrúa, México, pp. 85-100.

Guha, Ranajit, 1988, "Preface”, en Ranajit Guha y Gyatri Spivak (eds.), Selected Subalternal Studies, Oxford University Press, Nueva York.

Heller, Agnes, 2008, “1. Los dos pilares de la ética moderna”, en Agnes Heller y Ángel Prior (eds.), Los dos pilares de la ética moderna: diálogos con Agnes Heller, Libros del Innombrable, Biblioteca Golpe de Dados, núm. 75, España, pp. 3-25.

Ingarden, Roman, 2001, Sobre la responsabilidad, Caparrós Editores, Madrid.

Lizot, Jacques, 1985, Tales of the Yanomami: Daily Life in the Venezuelan Forest, Cambridge University Press, Cambridge. 
Marcus, George E. y Michael M. Fischer, 1986, Anthropology as Cultural Critique: An Experimental Moment in the Human Sciences, The University of Chicago Press, Chicago.

Meskell, Lynn y Peter Pels, 2005, "Introduction: Embedding ethics", en Peter Pels (ed.), Embedding Ethics: Shifting Boundaries of the Anthropological Profession, Berg Publishers, Oxford, pp. 1-26.

Mignolo, Walter, 1998, "Posoccidentalismo: el argumento desde América Latina”, en Santiago Castro-Gómez y Eduardo Mendieta (coords.), Teorías sin disciplina. Latinoamericanismo, poscolonialidad y globalización en debate, University of San Francisco, Miguel Ángel Porrúa, México, pp. 31-58.

Nishida, Kitaro, 1995, Indagación del bien, Gedisa, Barcelona.

Pels, Peter, 2005, “'Where There Aren't No Ten Commandments': Redefining Ethics During the Darkness in $\mathrm{El}$ Dorado Scandal", en Peter Pels (ed.), Embedding Ethics: Shifting Boundaries of the Anthropological Profession, Berg Publishers, Oxford, pp. 69-99.

Ramos, Alcida Rita, 2004, "Los yanomami en el corazón de las tinieblas blancas", en Relaciones, vol. 25, núm. 93, El Colegio de Michoacán, México, pp. 17-47.

Said, Edward W., 2009, Orientalismo, Random HouseMondadori, México.

Spivak, Gayatri Chakravorty, 2010 "Can the Subaltern Speak", en Rosalind C. Morris (ed.), Reflections on the History of an Idea. Can the Subaltern Speak?, Columbia University Press, Nueva York, pp. 21-78.

Stocking, George (ed.), 1991, Colonial Situations. Essays on the Contextualization of Ethnographic Knowledge, The University of Wisconsin Press, Wisconsin y Londres.

Tierney, Patrick, 2000, Darkness in El Dorado: How Scientist and Journalist Devastated the Amazon, W. W. Norton \& Company, Inc., Nueva York.

Thiebaut, Carlos, 1992, "Neoaristotelismos contemporáneos", en Victoria Camps, Osvaldo Guariglia y Fernando
Salmerón (eds.), Concepciones de la ética, Trotta, Madrid, pp. 29-52.

Tseëlon, Efrat, 1992, "Self Presentation trough Appareance: A Manipulative vs. Dramaturgical Approach", en Symbolic Interaction, vol. 15, núm. 4, pp. 501-514.

Ushiñahua, Charito, 2008, "Yanomami Indian's: The Fierce People?”, en línea: <http://www.amazon-indians. org/yanomami.html $>$.

Vattimo, Gianni, 2010, Adiós a la verdad, Gedisa, Barcelona.

Von Wrigth, Georg Henrik, 1998, Un ensayo de lógica deóntica y la teoría general de la acción, Instituto de Investigaciones Filosóficas-Universidad Nacional Autónoma de México, México.

- 2001, Normas, verdad y lógica, Fontamara, México.

Wells, H. George, [1895] 2002, La máquina del tiempo, Alianza, Madrid.

Williams, Bernard, 2006, "El reconocimiento de la responsabilidad", en Mark Platts (comp.), Conceptos éticos fundamentales, Universidad Nacional Autónoma de México, México, pp. 168-200.

Wilson, Richard A., 2004, "The Trouble with Truth. Anthropology's Epistemological Hypochondria”, en Anthropology Today, vol. 20, núm. 5, pp. 14-17.

\section{Referencias electrónicas}

American Anthropological Association (AAA), 1998, Code of Ethics of the American Anthropological Association, en línea: <http://www.aaanet.org/committees/ethics/ ethcode.htm $>$.

Colegio de Antropólogos de Chile, 2003, Código de ética de la Asociación Antropológica Americana, Debbie Guerra y Juan Carlos Skewes (trads.), en línea: http://www.colegioantropologos.cl/web/index.php?option=com content\&view $=$ article\&id $=266$. 